\title{
Deterioration in brick buildings: hygrothermal performance and measures to save them
}

\author{
Pär Johansson ${ }^{1, *}$ and Paula Wahlgren ${ }^{1}$ \\ ${ }^{1}$ Chalmers University of Technology, Department of Architecture and Civil Engineering, SE-412 96 Gothenburg, Sweden
}

\begin{abstract}
Many former industrial building sites in Sweden have been abandoned and left to deteriorate. Nowadays, there is a large interest to refurbish and retrofit these buildings for other purposes. Commercial and housing developers are attracted to these areas which are often in the outskirts of the city centers. There are several challenges facing architects and engineers to preserve these buildings, also connected to cultural heritage demands. The aim of this study is to propose measures to preserve cultural heritage buildings. A brick building in Gothenburg, on the Swedish west coast, is used as a case study. The building was used for paper production until 2005. After that, it deteriorated quickly after the heating was turned off. The rapid decay affected the hygrothermal performance as well as the load-bearing capacity of the structure. Small scale laboratory investigations of the building materials show a high degree of decay. Measurements of temperature and relative humidity is used to monitor the hygrothermal performance. Observations show that the brick masonry has heavy salt efflorescence and is in need of further protective measures.
\end{abstract}

\section{Introduction}

The majority of the buildings in Sweden was constructed more than 40 years ago. They were typically designed for a service life of at least 100 years. During this time there is a need for several major and minor retrofits and also for continuous maintenance of the building envelope due to degradation by natural aging, incidental damages, or because of outdated building techniques. The most common cause for renovation is that there is an immediate need, or that different components have reached their end of service life [1]. In these cases, the time for planning and implementing the retrofitting measures is limited. Therefore, practical guidelines based on building physics performance indicators could contribute to developing continuous maintenance plans to avoid performance failure.

There is a delicate interaction between temperature and relative humidity in structures. A reduction of the temperature in a construction (caused by for example additional insulation) can result in a high relative humidity or increased air movements, which also can cause problems. An energy efficiency measure may also enhance thermal bridges and cause surface contamination due to increased air movement. By implementing preventive actions at the right time and by applying efficient renovation strategies, funds can be used more efficiently leading to better performing buildings and more satisfied users. The aim of this study is to propose measures to protect cultural heritage buildings. Results from a field investigation in an old industrial brick building, see Fig. 1, located in a cold and moist climate in Sweden is used to investigate the degradation of materials in the structure. A homogenous brick masonry wall in the building is investigated by small scale measurements of thermal conductivity, heat capacity and moisture diffusivity, and by large scale measurements of heat flow, temperature and moisture conditions. The building has been unoccupied for a number of years without a controlled climate inside. It is exposed to the rain and wind, facing the dominant southwest direction, and regular freeze-thaw intervals.
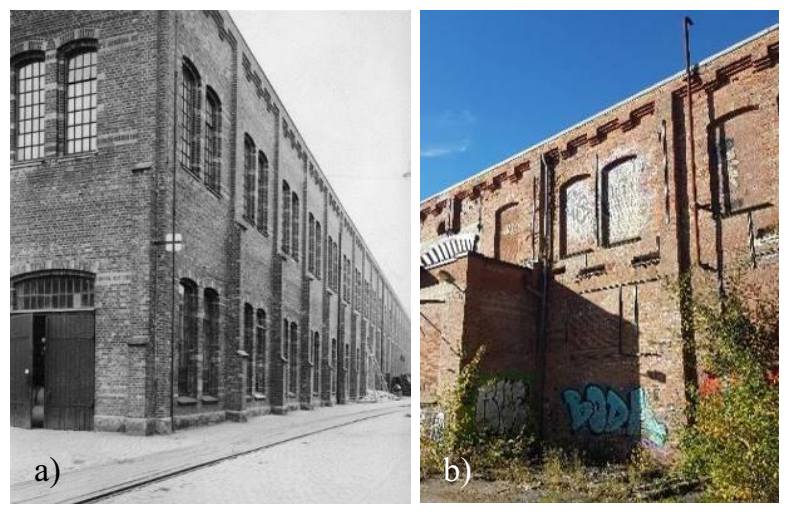

Fig. 1. (a) The building from 1896 in south of Gothenburg, photo from 1918, (b) The exterior of the tested external wall.

\subsection{Background}

In research the last years focus has been on energy efficiency with less attention to the long-term performance and durability in other aspects, such as indoor environmental quality, thermal comfort and moisture safety. The users of the building have demands

\footnotetext{
* Corresponding author: par.johansson@,chalmers.se
} 
on a good and healthy indoor environment, but also the society demands that the building shall perform according to certain standards. These are often given in building codes, where for example the allowed energy use for heating is defined together with other performance criteria. Some performances are easily followed up and validated by using measurements of, for example, the energy use and indoor temperature. Other performances, such as moisture performance of the building envelope, are more difficult to control and follow up because of the lack of adequate performance criteria as well as of appropriate control techniques. For these cases, performance failures are discovered first when there is a visible damage to the construction or when there are complaints from the users (unpleasant smell, damp air, etc.). At that stage it is too late to implement preventive actions to avoid costly repair work.

Most of the available methods for performing risk assessment concerns the structural integrity of the building. Of these, non-destructive methods are of large practical interest and in particular those that can be used on a large variety of building materials. The methods require knowledge of the building and the specific materials in the construction. Material data can be obtained by frost dilatometry which is a methodology for identification of the frost resistance of bricks [2]. This data is used to support the decision on which retrofitting measures is suitable for a specific building, for instance repairing brick and mortar or installing hydrophobic surface treatment on the exterior in connection to a renovation measure.

Up until the early 1900s, hydraulic lime mortars were used in brick masonry buildings in Sweden. These have large tolerances to movements caused by temperature and moisture fluctuations, while one of the disadvantages is the longer curing time compared to mixtures of lime and cement mortar, which are more common today. In a previous study [3], a full-scale laboratory experiment showed that the moisture content in the wall was highly influenced by the properties of the brick and mortar. The time before the wall was saturated differed with a factor of 6 between the least and most permeable bricks while the type of mortar heavily influenced the drying of the wall.

Often moisture from the outside is the major moisture source. Consequently, one solution may be to apply a water repellent substance on the surface. This measure leads to less moisture into the construction [4]. There are several different impregnations available which can be applied to the surface of the façade. However, for brick masonry it is important to make sure that the surface is free from cracks and other defects. Otherwise, the impregnation can have adverse effect on the performance of the façade, since the drying out capacity is decreased while water can still enter the cracks. Slapø et al. [5] tested four different impregnations on a brick wall with fresh mortar. They recommend great care when using the substances on brick walls in areas with much driving rain and frequent freeze-thaw cycles.

\subsection{Case study building}

The case study building was constructed in 1896 and has been reconstructed several times since then. The building was used for paper production which was in operation until the paper mill was closed in 2005. Left deserted, the building degraded rapidly due to the cold and humid climate. The heritage values and character defining elements of the building have been evaluated and one of the features that is considered important is the brick façade. Therefore, interior insulation is thought to be an interesting solution to reach enough energy performance whilst preserving the outer surface. A small test room was constructed inside the building to investigate the hygrothermal performance of the wall. The test room was insulated (170 $\mathrm{mm}$ mineral wool) in the floor, walls and roof while leaving the external brick wall exposed, see Fig. 2.

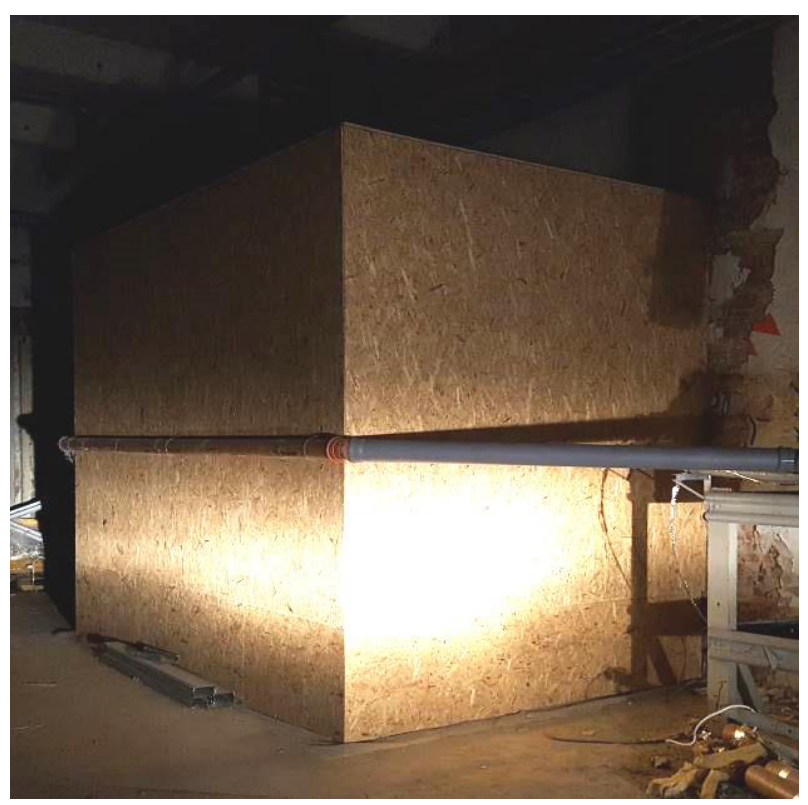

Fig. 2. Small test room inside the building.

The test room was heated to around $23^{\circ} \mathrm{C}$ and ventilated by natural ventilation through two openings with $0.5 \mathrm{~h}^{-1}$ air exchange rate, measured by tracer gas method [6]. The air in the room was circulated by a fan to create homogenous temperature and moisture conditions in the entire room. The temperature and relative humidity of the air was continuously measured by two sensors. The measurement accuracy is $\pm 2.5 \%$ for relative humidity in the range of 10 to $90 \%$ and $\pm 0.5^{\circ} \mathrm{C}$ for temperature at $25^{\circ} \mathrm{C}$. The temperature can be measured between -40 to $85^{\circ} \mathrm{C}$. A weather station monitors the temperature, relative humidity, wind speed and rain intensity on a free field, nearby the façade.

\subsection{Hygrothermal sensors and wall preparation}

The wall is equipped with 10 hygrothermal sensors (see Fig. 3) that register the temperature and relative humidity. The sensors are wireless Sahlén sensors (wood moisture sensors) which measure the weight percentage moisture in a piece of birch around the sensor. The 
measurement range corresponds to $60 \%$ to $100 \% \mathrm{RH}$. The size of the sensors is $40 \mathrm{~mm} \times 13 \mathrm{~mm}$ (height $\mathrm{x}$ diameter), inserted in a $15 \mathrm{~mm}$ wide hole in the wall.
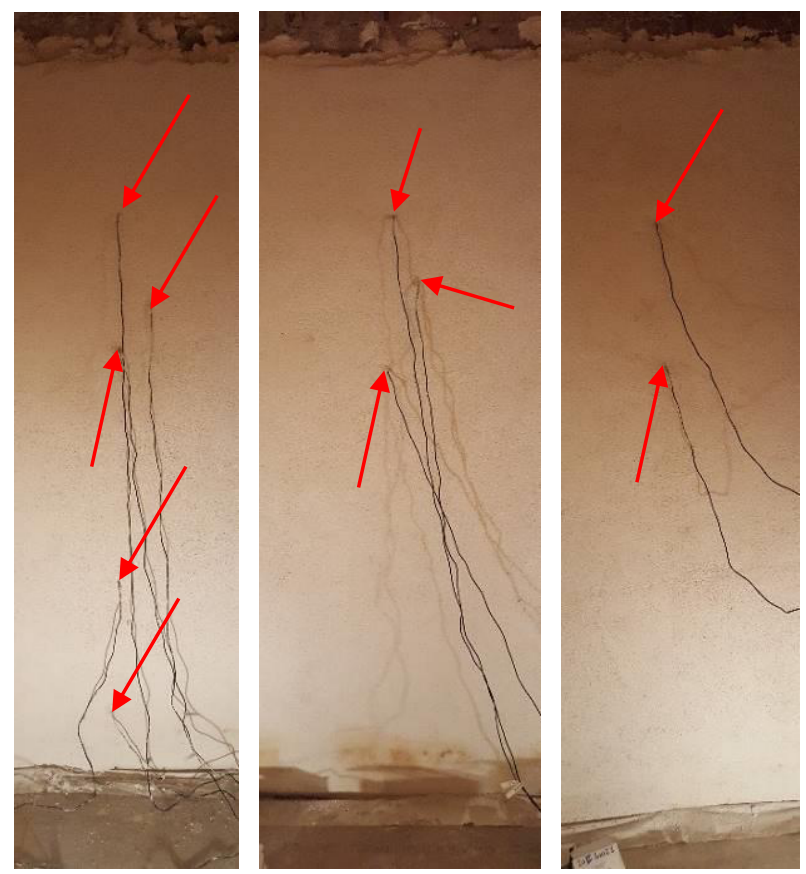

Fig. 3. Hygrothermal sensors (marked with arrows) in the middle of the bricks and surface of the plastered brick wall.

Prior to the installation of the sensors, the existing plaster was removed from the interior brick surface. There was substantial capillary suction from the ground and from the exposure to driving rain from south-west, which is the dominant wind direction. The old plaster was loose up to approximately 1 meter above the concrete slab and came down easily, without applying force, while the upper part of the wall required demolition hammer to remove the plaster. The initial estimations showed that the rate of water flow in the bricks was approximately three times higher than that in modern bricks [7].

In the preparation of the field study, the temperature and relative humidity were measured inside the case study building between 20 December, 2017, and 29 January, 2018 [7]. The indoor temperature was on average $4.1{ }^{\circ} \mathrm{C}$ and varied between $0.9^{\circ} \mathrm{C}$ and $9.5^{\circ} \mathrm{C}$. The relative humidity was on average $92.8 \%$ and varied between $66.7 \%$ and $100 \%$. This can be compared to the outdoor temperature and relative humidity in a nearby weather station which was on average $3.0^{\circ} \mathrm{C}$ and $87 \%$ relative humidity. The outdoor temperature varied between $-7.9^{\circ} \mathrm{C}$ and $10.0^{\circ} \mathrm{C}$ and the relative humidity varied between $48.0 \%$ and $100 \%$. This gives a moisture supply of $0.8 \mathrm{~g} / \mathrm{m}^{3}$ in the building. The moist and cold climate give several challenges for preserving and maintaining the building for future use.

\section{Hygrothermal measurement results}

The preparatory measurements of the hygrothermal performance was reported in [7] while measurements of the heat flux in different parts of the wall was presented in [6]. The conclusion was that the measured heat flux deviated from the expected calculated heat flux. The calculations gave a U-value of $1.0-1.5 \mathrm{~W} / \mathrm{m}^{2} \mathrm{~K}$, dependent on the moisture content in the brick, while the measurements gave a U-value of $1.3-2.0 \mathrm{~W} / \mathrm{m}^{2} \mathrm{~K}$. The deviation could be explained by differences in the solar radiation exposure on different parts of the façade (see Fig. 1), evaporation of water from the wall and different level of moisture content in the brick masonry.

The heating in the room was started on 20 December 2017. The temperature varied between $9^{\circ} \mathrm{C}$ and $14^{\circ} \mathrm{C}$ and was on average $12.8^{\circ} \mathrm{C}$. The relative humidity varied between $68 \%$ and $81 \%$ and was on average $78.9 \%$. On 21 January 2018, an additional radiator was installed which gave a more stable climate with an average temperature of $21.9^{\circ} \mathrm{C}$ and relative humidity of $76.5 \%$.

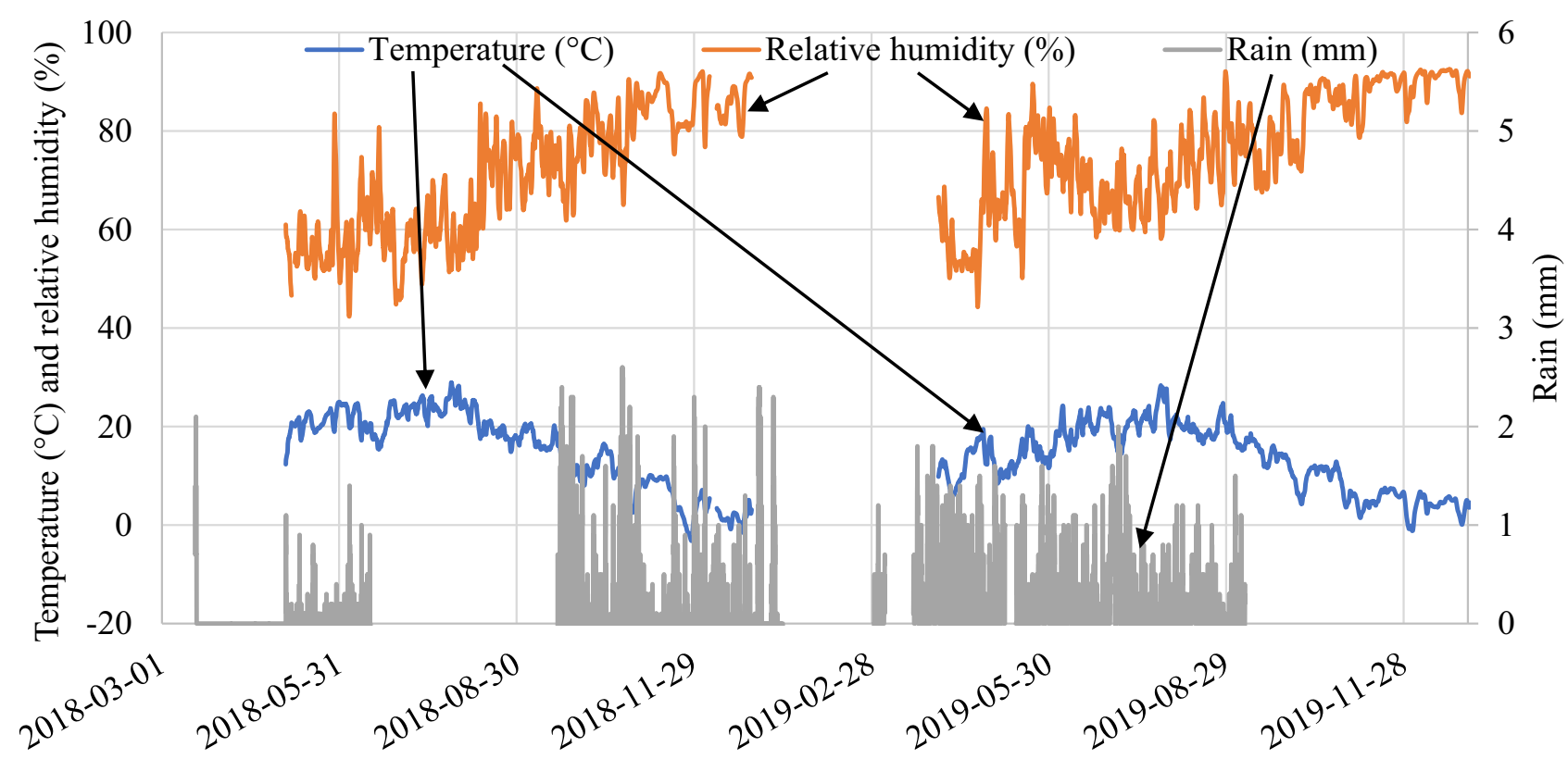

Fig. 4. Outdoor temperature, relative humidity and rain load on the wall from March 2018 to January 2020, sliding 24-hour average. 


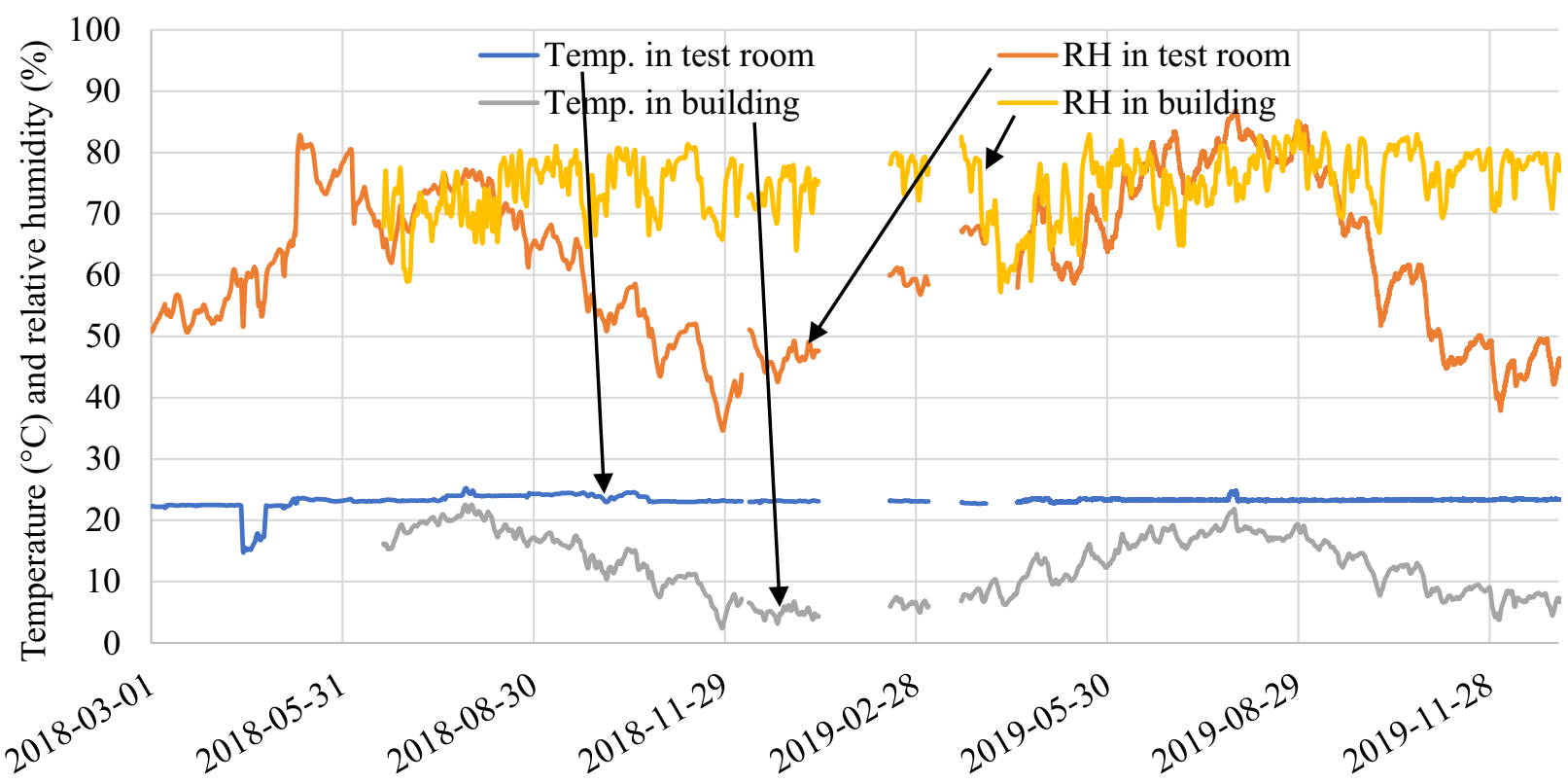

Fig. 5. Temperature and relative humidity in test room and in building, from March 2018 to January 2020, sliding 24-hour average.

The measurements of the outdoor and indoor temperature, relative humidity and rain load are presented in Fig. 4 and Fig. 5. The measurements inside the test room and building started in March 2018, while the weather station and the outdoor climate were monitored from May 2018.

After the measurements started in the wall, there were several major disturbances in the electric power supply to the measurement devices and sensor malfunction. The switchboard had to be replaced after condensed water found its way into the connections, causing short circuit. There were also problems with rodents causing short circuits disabling the power supply. The major data losses are summarized in Table 1 for the sensors in the air and in the wall.

The measurements of the temperature and relative humidity in the middle of the wall at different heights above the ground are presented in Fig. 6 and Fig. 7.
Table 1. Data losses from sensors outdoor, in the test room and in the building.

\begin{tabular}{|c|c|c|c|}
\hline Outdoor & Test room & $\begin{array}{c}\text { Building and } \\
\text { inside wall }\end{array}$ & Rain gauge \\
\hline $2018-05-07$ & $2018-12-07$ & $2018-12-07$ & $2018-06-16$ \\
$2018-05-08$ & $2018-12-10$ & $2018-12-10$ & $2018-09-20$ \\
\hline $2018-12-07$ & $2019-01-13$ & $2019-01-13$ & $2019-01-13$ \\
$2018-12-10$ & $2019-02-15$ & $2019-02-15$ & $2019-03-01$ \\
\hline $2018-12-29^{*}$ & $2019-03-06$ & $2019-03-06$ & $2019-03-06$ \\
$2019-04-03^{*}$ & $2019-03-21$ & $2019-03-21$ & $2019-03-21$ \\
\hline & $2019-04-03^{*}$ & & $2019-05-07$ \\
& $2019-04-17^{*}$ & & $2019-05-13$ \\
\hline & & & $2019-09-07 *$ \\
& & & - \\
\hline
\end{tabular}

*sensor malfunction 


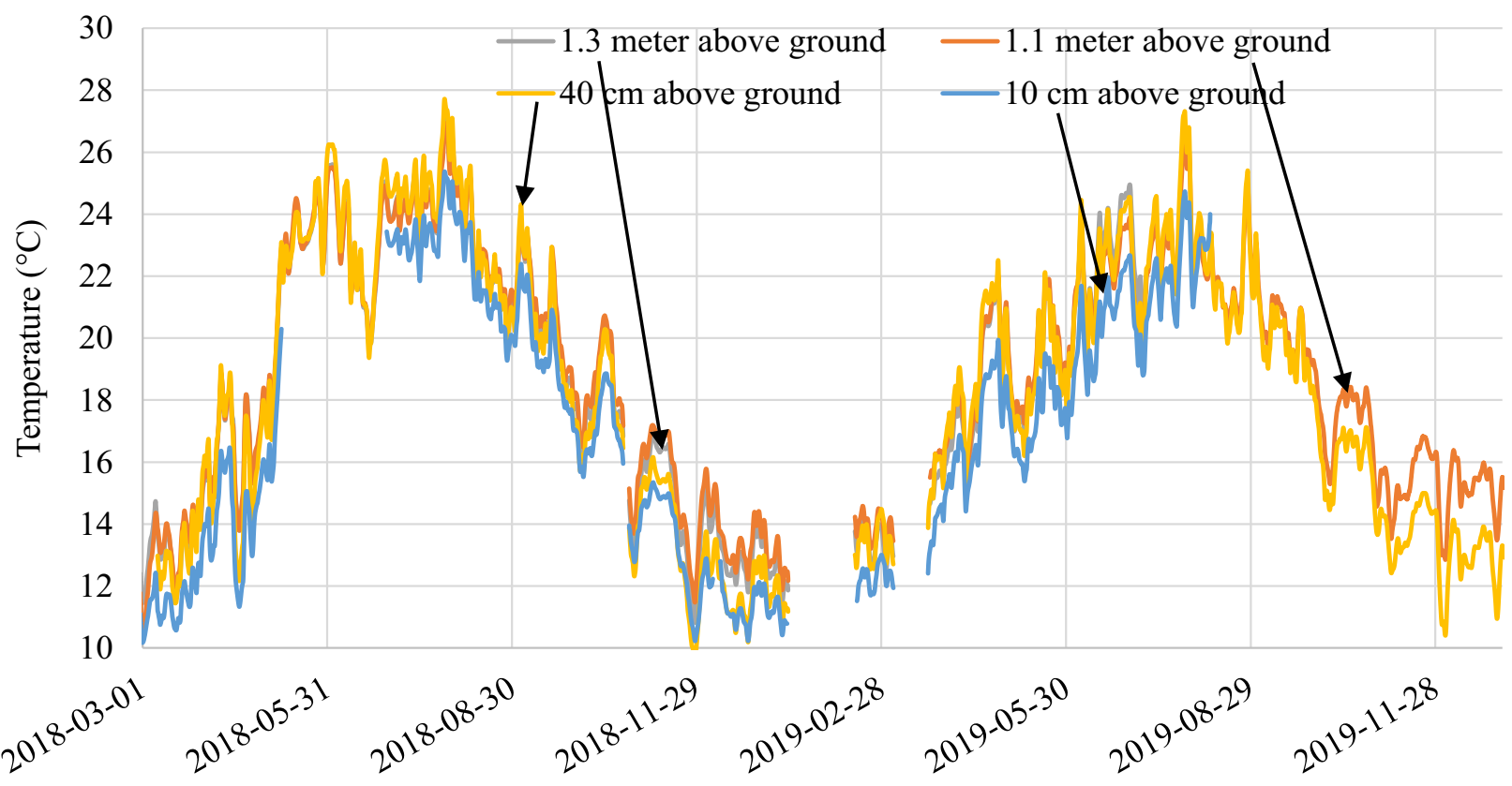

Fig. 6. Temperatures in the middle of the wall on different heights, from March 2018 to January 2020, sliding 24-hour average.

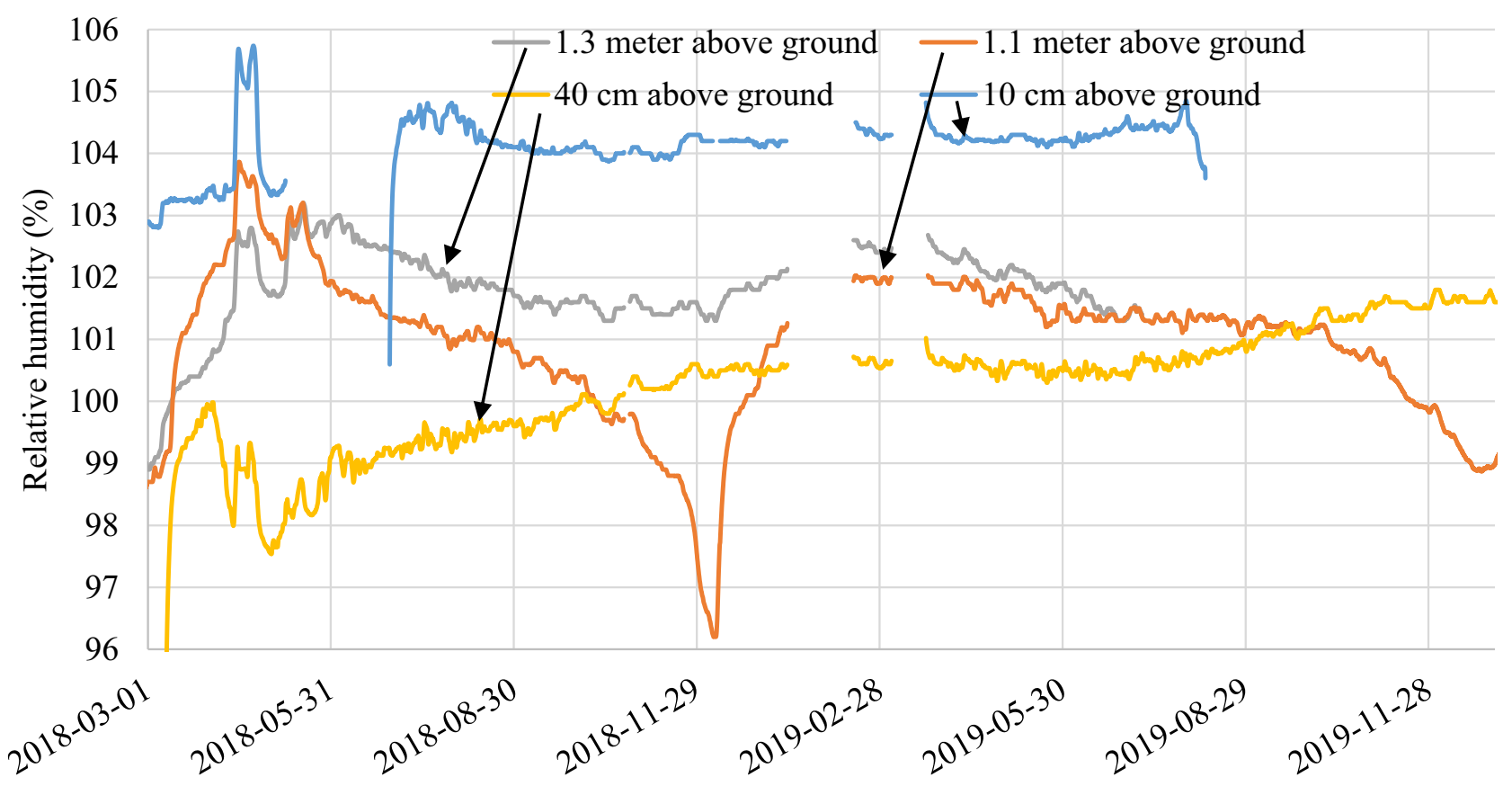

Fig. 7. Relative humidity in the middle of the wall at different heights, from March 2018 to January 2020, sliding 24-hour average.

According to the measurements, the temperature is highest further up in the wall, where it can be expected that the impact of the surrounding ground is smaller. The relative humidity is above $100 \%$ in the measurements. This is due to the interpretation of the measurement results in the sensor itself. The relative humidity is highest close to the slab while it varies between the measurement positions in the upper part of the wall. This could be cause by crack in the mortar or bricks, as well as whether the sensor is in contact with brick or mortar inside the wall.
Moisture can influence the temperatures by different phenomena, for example increased thermal conductivity and evaporation. During rainfall, the lower parts of the wall receive a large amount of water, from upper parts and also from splashing, which can be a major contributor to moisture on walls. A moist surface will be cooled by evaporation, which can result in several degree lower surface temperatures on the rain exposed surface, which will also affect the temperatures inside the wall. The length of the cooling period is difficult to estimate and depends on the duration of the rain and the absorption of the brick. The building is located in an area 
with frequent rains. One of the studied periods was unusually dry (summer 2018). For this case, the temperature difference between cooler lower parts and slightly warmer upper parts was smaller than other studied periods. This means that there might still be evaporation but that the source might not be rain but possibly evaporation of moisture from the ground. That moisture was rising from the ground was evident from the condition of the wall.

\subsection{Salt deposition and efflorescence}

Already in the end of January 2018 there was formation of salt crystals (salt efflorescence) on the inside of the brick mortar. The formation started closer the ground, in the lower part of the wall where the moisture content could be expected to be higher. The evaporation from the wall increased substantially when the temperature was increased which accelerated the deposition of salt crystals on the interior surface.

Due to the detrimental effects by the salt efflorescence on the brick masonry, the decision was made to install a layer of lime-based mortar on the interior of the wall. This was performed in the beginning of May 2018, which is visible as an increased relative humidity in Fig. 7. The mortar acts sacrificially to prevent the brick from deteriorating but does not stop efflorescence. Consequently, after the mortar was applied, the efflorescence continued, along with the degradation of the interior surface by the salt deposition. The salt crystals are continuously brushed off the wall and the mortar need to be regularly inspected to not deteriorate and expose the brick masonry. It is also important to make sure that the mortar is attached to the load-bearing part of the brick masonry so that no pockets of air can be formed between the layers where the salt efflorescence can continue to deteriorate the brick masonry.

With time, it is expected that the salt efflorescence will decrease as the salts inside the brick masonry is transported to the surface. However, depending on the source of the salt, the time for this process may vary. As the building is located approximately $7 \mathrm{~km}$ from the sea, it is also expected that some salt may be added from the rain into the wall.

\subsection{Measures to protect the building}

The long-term durability of the building and the loadbearing structure need to be secured. As the heating in the buildings is detrimental to the brick mortar, and the cold and humid climate is as well, measures are needed. A solution that was implemented in November 2019, was to add a plastic wrapping around the entire building, see Fig. 8. The roof was already, from the start of the study, covered by a weather protection tent to prevent water leakage from rain into the building. The measurements will continue also after the plastic wrapping has been installed and the hygrothermal performance of the brick masonry is continuously monitored.

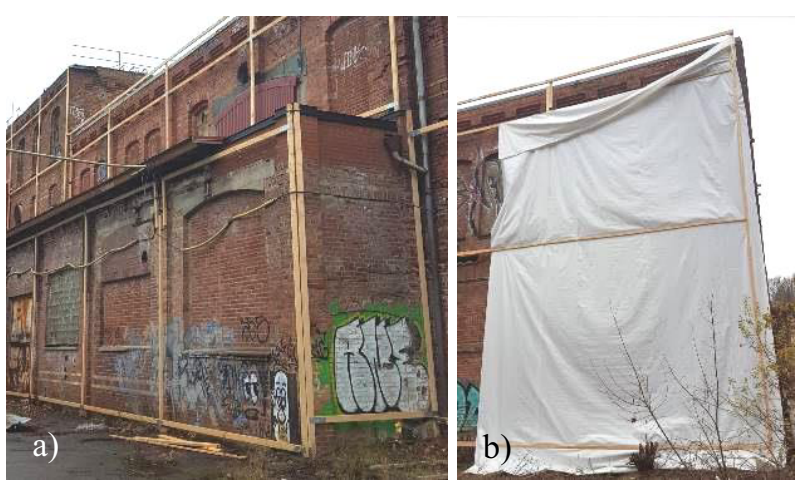

Fig. 8. (a) Exterior of the building prepared to be covered in plastic wrapping. (b) Part of the building covered in plastic, from November 2019.

\section{Conclusions}

There are several challenges facing architects and engineers to preserve brick buildings with cultural heritage values. Practical guidelines based on building physics performance indicators could contribute to developing continuous maintenance plans to avoid performance failure in these buildings. In this paper, a field investigation in an old industrial brick building was used to study the degradation of materials in the structure. A homogenous brick masonry wall in the building was investigated by small scale measurements of thermal conductivity, heat capacity and moisture diffusivity, and by large scale measurements of heat flows, temperature and moisture conditions. A small test room was constructed inside the building to investigate the hygrothermal performance of the wall. There was substantial capillary suction into the wall from the ground and from the exposure to driving rain from south-west, which is the dominant wind direction. The relative humidity is highest close to the slab while it varies between the measurement positions in the upper part of the wall. The evaporation from the wall increased substantially when the temperature was increased inside the test room, which accelerated the deposition of salt crystals (salt efflorescence) on the interior surface. With time, it is expected that the salt efflorescence will decrease as the salts inside the brick masonry is transported to the surface. Therefore, it is important to cover the wall on the interior by some layer (e.g. lime mortar) which can be easily attached to the wall and replaced when it has deteriorated. The building is in need of further protective measures to reduce the water supplied to the wall. Therefore, a plastic wrapping was installed around the building. The consequences of this will be monitored through the continued measurements in the wall. The aim of the study is to provide performance indicators to develop practical guidelines for the restoration of this type of building. The decay is rapid once a building is abandoned. Therefore, continuous maintenance and heating is essential if a building, with heritage values, is to be preserved. 
This study is supported by the Swedish Energy Agency through the project $42856-1$. We would also like to thank MölnDala Fastighets $\mathrm{AB}$ and Pontus Johansson, Gabriella Josefsson, Maria Daoud Rajha and Mathis Gelot for performing the laboratory investigations.

\section{References}

1. L. Thuvander, P. Femenias, M. Xygkogianni, B. Brunklaus, Renoveringsbarometern: Omfattning och karaktär av renoveringar i bostadshus Bygg \& Teknik (2/16) p. 23 (2016)

2. P. Mensinga, J. Straube, C. Schumacher, Assessing the Freeze-Thaw Resistance of Clay Brick for Interior Insulation Retrofit Projects Proc. 11th Int. Conf. on Thermal Performance of the Exterior Envelopes of Whole Buildings Clearwater Beach, FL, USA (2010)

3. P. Johansson, S. Geving, C.-E. Hagentoft, B.P. Jelle, E. Rognvik, A.S. Kalagasidis, B. Time, Interior insulation retrofit of a historical brick wall using vacuum insulation panels: Hygrothermal numerical simulations and laboratory investigations Building and Environment 79 pp. 31-45 doi: 10.1016/j.buildenv.2014.04.014 (2014)

4. K. Sandin, Vattenavvisande impregnering Fullskaleförsök 1992-2002 Lund University, Division of Building Materials Lund, Sweden (2003).

5. F. Slapø, T. Kvande, N. Bakken, M. Haugen, J. Lohne, Masonry's Resistance to Driving Rain: Mortar Water Content and Impregnation Buildings 7 (3) p. 70 doi: 10.3390/buildings 7030070 (2017)

6. P. Johansson, P. Wahlgren, P. Eriksson, Field Testing of Interior Super Insulation Materials on a Brick Wall in an Industrial Building Proc. 13th Int. Conf. on Thermal Performance of the Exterior Envelope of Whole Buildings Clearwater Beach, FL, USA (2019)

7. P. Johansson, P. Wahlgren, Interior insulation retrofit of a brick wall using super insulation materials: design of a field testing in an industrial brick building Proc. 7th Int. Building Physics Conf. Syracuse, NY, USA (2018) 